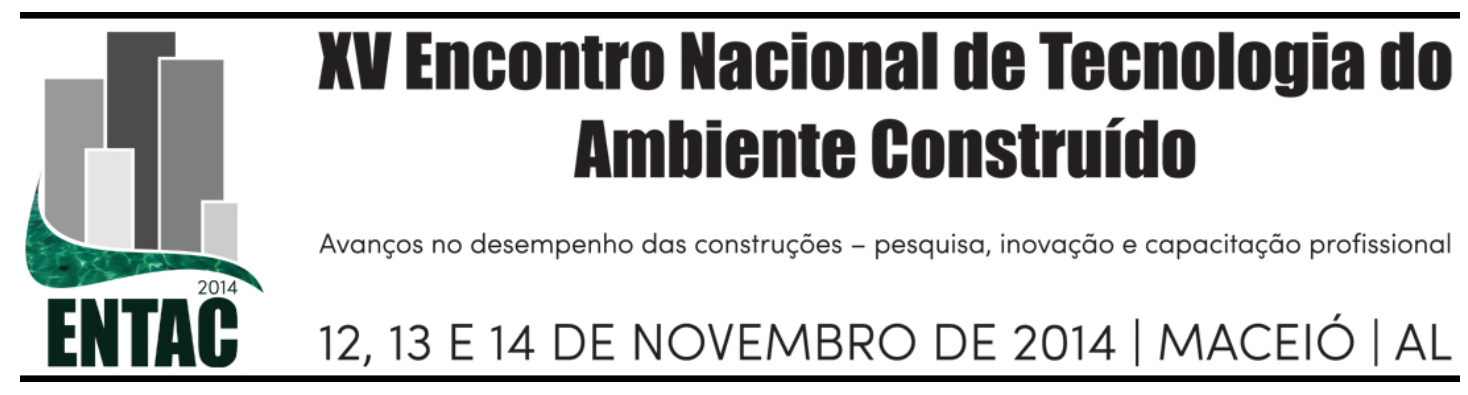

\title{
ANÁLISE DAS PRÁTICAS DE SUSTENTABILIDADE NO USO RACIONAL DA ÁGUA EM CANTEIROS DE OBRAS
}

\author{
ZEULE, Ludimilla de O. (1); SERRA, Sheyla M. B.(2) \\ Núcleo de Pesquisa em Racionalização e Desempenho de Edificações (NUPRE), Programa de Pós- \\ graduação em Estruturas e Construção Civil (PPGECiv), Universidade Federal de São Carlos (UFSCar) \\ (1) Doutoranda, zeule.eu@gmail.com, (2) Professora, sheylabs@ufscar.br
}

\begin{abstract}
RESUMO
A prática da sustentabilidade e sua aplicação na construção pode ser considerada recente, necessitando de estudos que procurem detalhar as diferentes possibilidades existentes. Este artigo apresenta um método para identificação e comparação de práticas de sustentabilidade em canteiros de obras. A pesquisa original propõe uma lista de itens que facilitam a implementação da sustentabilidade em canteiros de obras, visando promover desenvolvimento tecnológico e disseminação dos aspectos da sustentabilidade voltada para a fase de execução dos empreendimentos. Identificou-se que existem seis principais temas que precisam serem mais investigados, sendo que este artigo se relaciona com o tema "Uso Racional da Água" nos canteiros de obras. No caso da água, por ser um recurso natural, a mesma tem sido fonte de grande preocupação para a sociedade, notando-se um crescimento de conscientização em geral, alcançando também os ambientes de trabalho. Os principais itens a serem avaliados sobre uso da água em atividades e processos dentro dos canteiros de obras abordam: captação de águas pluviais, captação de águas cinzas, reúso de águas pluviais e cinzas, condições das instalações tanto de águas pluviais e cinzas quanto de águas servidas, periodicidade de manutenção das instalações de águas servidas, tipo de abastecimento de água para o canteiro, palestras e orientação aos operários, e emprego de louças e metais sanitários economizadores nas instalações provisórias do canteiro visando a redução do consumo de água na fase de execução. O artigo utiliza o método de estudo de caso, composto por quatro obras, de diferentes tipologias e localizações geográficas, podendo ser avaliada quais as maiores dificuldades e melhores ocorrências de práticas sustentáveis em relação ao uso da água nos canteiros de obras.
\end{abstract}

Palavras-chave: Sustentabilidade, Uso racional da água, Canteiro de obras, Gestão ambiental.

\begin{abstract}
The practice of sustainability and its application in construction can be considered recent, requiring studies attempting to detail the different possibilities. This paper presents a method for the identification and comparison of sustainability practices on construction sites. The original research proposes a list of items that facilitate the implementation of sustainability in construction sites, aiming to promote technological development and dissemination of aspects of sustainability facing the execution phase of the ventures. It was identified that there are six major themes that need to be investigated further, and this article relates to the theme "Rational Use of Water" at construction sites. In the case of water, as a natural resource, it has been of great concern to society, noting an increase of awareness in general, also reaching workplaces. The main items to be evaluated on water use in activities and processes within the construction site address: rainwater harvesting, greywater capture, reuse of rainwater and gray, conditions of facilities both rainwater and gray water as served, frequency of maintenance of wastewater facilities, type of water supply to the building, lectures and guidance to workers and job-saving sanitary ware and metal construction of temporary facilities in order to reduce water consumption in the execution phase. The article uses the case study method, consisting of four articles of various types and geographical locations, which can be evaluated more difficulties and occurrences of sustainable best practices in relation to water use at construction sites.
\end{abstract}

Keywords: Sustainability, Rational use of water, Construction site. 


\section{INTRODUÇÃo}

Identificada normalmente como uma indústria que consome grande parte dos recursos naturais, a construção civil tem considerável influência na gestão do meio ambiente e, de certa forma, desencadeou a adoção de posturas sustentáveis pelos seus agentes. A questão da sustentabilidade passou a ser discutida por vários especialistas e sociedade a partir da década de 80 e visava, enquanto definição geral, a "suprir as necessidades da geração presente sem afetar a habilidade das gerações futuras de suprir as suas" (WORLD COMMISSION ON ENVIRONMENT AND DEVELOPMENT, 1987).

Com isso, verificou-se ao longo do tempo a utilização de diferentes práticas sustentáveis no ciclo produtivo da construção e a busca da certificação em vários empreendimentos, procurando registrar as inovações para a sociedade e como forma também das empresas se manterem competitivas no mercado. Os selos de certificações funcionam como um parâmetro de qualidade incorporado à edificação. Atualmente existem várias certificações de sustentabilidade construtiva, originadas em diferentes partes do mundo, à disposição dos empreendedores e da própria sociedade.

Segundo United States Green Building Council (USGBC, 2013), o Brasil é o quarto país no ranking mundial de construções verdes com 51 prédios certificados e $525 \mathrm{em}$ processo de certificação, construídos a partir de 2007, atrás apenas dos Estados Unidos, Emirados Árabes Unidos e China. Para esse Conselho, o desenvolvimento da indústria da construção sustentável envolve a adoção de boas práticas e um processo integrado de concepção, construção e operação de edificações e de espaços construídos.

Dessa forma, pode-se afirmar que o processo de certificação deve considerar também o processo de execução das obras. Para Cardoso; Araújo (2007), a etapa de construção de um edifício responde por uma parcela significativa dos impactos negativos causados ao meio ambiente, principalmente os relacionados às perdas de materiais e à geração de resíduos e os referentes às interferências na vizinhança da obra e nos meios físico, biótico e antrópico do local onde a construção é edificada.

A construção sustentável passa a ser compreendida e desenvolvida a partir de ações que combatam crises e solucionem o problema ecológico, por meio do uso de tecnologias e materiais adequados, criando construções que sejam úteis não somente ao usuário, mas também ao meio ambiente. Tem por princípios o uso de materiais recicláveis, utilização racional de água, eficiência energética sem deixar de proporcionar conforto ao usuário (VALENTE, 2009).

Existe uma diversidade de práticas que ajudam a reduzir os impactos e que precisam ser mais bem conhecidas. Dessa forma, este artigo se concentrará em apresentar diretrizes e soluções encontradas nas referências e em estudos de caso para o uso racional da água em canteiros de obra e está baseado na pesquisa Zeule (2014).

\section{REVISÃO BIBLIOGRÁFICA}

\subsection{Gestão sustentável do canteiro de obras e da água}

A concepção do projeto de canteiro e gerenciamento das atividades realizadas em suas dependências são itens importantes no tocante à minimização dos transtornos causados durante a obra, ao bem estar dos operários e ao seu entorno. Assim, a gestão sustentável realizada nos canteiros visa, entre outros, a redução dos impactos ambientais causados pelo uso inadequado dos materiais/recursos ou componentes no canteiro de obras que podem ser minimizados ao se adotar políticas de planejamento e gestão. 
Ressalta-se a importância do canteiro de obras no contexto da sustentabilidade, já que as práticas sustentáveis com relação ao empreendimento são vistas com maior frequência focando a fase de ocupação, talvez pelo fato deser uma fase com maior consumo energético, possuir longoprazo de vida útil, bem como necessitar apresentar características que sirvam ao bem estar das pessoas que nele residirão. Normalmente, a fase de execução possui prazos menores e a ocupação dos trabalhadores é feita de forma parcial durante o dia. Entretanto, algumas diretrizes de sustentabilidade podem ser adaptadas e/ou utilizadas nas duas fases do empreendimento.

Brasil (2014) menciona que no âmbito da edificação, entende-se que alguns fatores são essenciais, tais como: adequação do projeto ao clima do local;a minimização do consumo de energia e otimização das condições de ventilação; uso da iluminação e aquecimento naturais; atenção para a orientação solar adequada, evitando-se a repetição do mesmo projeto em orientações diferentes; utilização de coberturas verdes. Desta forma, é possível notar que os anseios para a fase de ocupação podem ser previstos desde a fase de execução, ou seja, o canteiro também pode prever a sustentabilidade que envolve diversos fatores como, edificação, canteiro de obras e vizinhança, pessoas, fornecedores, materiais e processos.

Entende-se que os selos de certificação ambientais podem servir como uma forma de auxílio nas implementações, uma vez que contribuem para a minimização da poluição e do consumo surgidos nas etapas de produção, como dito por Halliday (2010). Para essa autora, a implantação dos selos de certificação sustentável traz benefícios ambientais, econômicos e sociais, e as construções que levam em conta os "critérios verdes" ganham com a diminuição de custos operacionais, melhora na segurança e saúde dos trabalhadores e ocupantes, uso racional dos recursos naturais, entre outras vantagens.

No tocante à gestão da água dentro dos canteiros de obras, observa-se que existem algumas pesquisas e orientações para o uso de estratégias de minimização e controle do consumo. Entretanto, ainda não há implantação massiva nos canteiros de obra, devido talvez à falta de fiscalização das normalizações estaduais e nacionais.

Para a Companhia Ambiental do Estado de São Paulo (CETESB, 2014) o reúso de água faz "parte de uma atividade mais abrangente que é o uso racional ou eficiente da água, o qual compreende também o controle de perdas e desperdícios, e a minimização da produção de efluentes e do consumo de água".

O manual internacional mais consultado e conhecido para reúso de água é o "Guidelines for Water Reuse" publicado em conjunto pela Environmental Protection Agency (EPA) e Agency for International Development em 2004 e reeditado em 2012, que tem por objetivo principal orientar o reúso da água em locais onde não há regulamentação para tal prática (EPA, 2012).

O Brasil possui diversos documentos de regulamentação, como a Norma Brasileira Registrada (NBR) 15527 (Associação Brasileira de Normas Técnicas (ABNT), 2007) que trata dos aproveitamentos de água de chuva para uso não potável; a Resolução ${ }^{\circ}$ 357 do Conselho Nacional do Meio Ambiente (CONAMA, 2005) que classifica as águas segundo a qualidade requerida para os seus usos preponderantes, em treze classes (entre elas, a água para abastecimento humano); a Política Nacional dos Recursos Hídricos (PNRH, Brasil, 1997); e a NBR 13969 (ABNT, 1997), que não é específica para reúso, mas tem um item definindo as classes de água de reúso e indicação de padrões de qualidade esperados, que descreve as unidades de pós-tratamento e sugere alternativas de disposição final de efluentes líquidos de tanques sépticos. 
Também existem várias recomendações e portarias da Agência Nacional de Vigilância Sanitária (ANVISA) que é a responsável por fiscalizar aspectos relacionados com a saúde das pessoas no Brasil. Segundo Brasil (2011), "toda água destinada ao consumo humano, distribuída coletivamente por meio de sistema ou solução alternativa coletiva de abastecimento de água, deve ser objeto de controle e vigilância da qualidade da água". Para comprovar a qualidade da água, devem ser seguidos parâmetros de referência internacional, como as metodologias propostas pela Organização Mundial da Saúde (OMS), entre outras.

De acordo com Giacchini (2011), o Brasil não dispõe de normatização técnica específica para os sistemas de reúso da água. Em geral, são adotados padrões referenciais internacionais ou orientações técnicas produzidas por instituições privadas, o que tem dificultado a aplicação desta prática no país. Para esse autor, a falta de legislação específica pode colocar em risco a saúde da população devido à falta de orientação técnica para a implantação e fiscalização.

\subsection{Práticas de uso sustentável da água em canteiros de obras}

De acordo com a Norma Regulamentadora $n^{\circ} 18$ que descreve as "Condições e Meio Ambiente de Trabalho na Indústria da Construção" (BRASIL, 2014b), a utilização de água nos canteiros de obras está relacionada com as demandas essenciais dos funcionários, e devem estar presentes nos itens básicos: a) refeitórios; b) instalações hidrossanitárias; c) bebedouros. De um modo geral, a água também deve estar presente nas frentes de trabalho para atender as demandas das atividades e serviços.

Segundo Reis; Souza e Oliveira (2004), o projeto das instalações hidráulicas em canteiros de obra contribui para a minimização de consumos excessivos da água, favorecendo a redução do impacto ambiental das obras de construção. Para estes autores, os canteiros de obras localizados em regiões que não possuam abastecimento público podem ser alimentados por poços artesianos, semi-artesianos, caminhões-pipa ou realizar-se a captação em um manancial próximo, quando este existir.

Desta forma, surge a necessidade de avaliação sistêmica do impacto gerado no entorno na fase de implantação do empreendimento. De acordo com a Associação Brasileira dos Escritórios de Arquitetura (AsBEA, 2012) é importante considerar que a região onde a obra está localizada interfere significativamente na avaliação da sustentabilidade, orientando, quase que obrigatoriamente, a adoção de alguma prática sustentável.

Entre as principais práticas encontradas está a "Captação de água pluvial e cinza" e consequente tratamento para reutilização em canteiro. As águas cinzas são provenientes dos chuveiros, lavatórios de banheiro, pias e tanques. É importante observar se as águas captadas (pluviais e/ou cinzas) são corretamente tratadas posteriormente para reúso e se os dispositivos de coleta de água de chuva são totalmente separados das instalações de água potável para impedir sua contaminação.

Um estudo experimental realizado por Santos et al. (2011) inclui a análise da eficiência do tratamento e avaliação do potencial de qualidade das águas cinzas tratadas, com baixo custo e fácil manutenção para a reutilização, onde a água cinza bruta é captada a partir de água de pias/lavatórios públicos e água de chuveiros de vestiários. O sistema mostrou potencial para recuperação das águas cinzas, mas as concentrações de alguns sólidos não eram baixas o suficiente para alcançar os limites apresentados em documentos legais e de referência.

Outra prática encontrada é o uso de "Tecnologias para águas servidas" onde pode ser considerada a qualidade das instalações de esgoto na obra, o método empregado para 
coleta das águas servidas (água de esgoto), a possível existência de reservatório para decantação de águas com material particulado, como argamassas endurecidas, gesso e outros resíduos que possam interferir no sistema de coleta de esgoto. Também deve ser avaliado se ocorre manutenção periódica deste tipo de instalações.

O esgotamento de água servida do canteiro pela rede pública, quando mal feito, pode apresentar vazamento e, consequentemente, percolação do esgoto por meio do solo, contaminando águas superficiais e subterrâneas (CARDOSO; ARAÚJO, 2007).

Outra prática é a "Redução do consumo" onde pode ser verificada se o canteiro dispõe de atividades para instruir os trabalhadores como gerar a economia de água e se eles colocam em prática o que lhes é informado. Para efetividade desta estratégia, é importante também utilizar equipamentos redutores de consumo de água. Alguns fabricantes de equipamentos sanitários disponibilizam no mercado torneiras com sensor de proximidade e vasos sanitários com duplo acionamento de descarga para líquidos e sólidos. $\mathrm{O}$ vaso funciona com meia descarga no caso dos líquidos e vazão completa para sólidos. Observa-se que tecnologias como essas têm sido empregadas em vários locais públicos devido ao grande desperdício de descargas e torneiras desreguladas que acabam gerando um desperdício de água.

\section{MÉTODO E INSTRUMENTO DE PESQUISA}

No campo metodológico, esta pesquisa é classificada como estudo descritivo de casos múltiplos, pois, de acordo com Yin (2009), este trabalho tem foco contemporâneo, cujos dados obtidos são de mais de um caso e objetiva responder a principal questão de pesquisa com estruturação do tipo "Como?" e "Por quê?".

A pesquisa também possui fator qualitativo, pois apresenta um sistema de pontuações baseado na escala de Likert, variando em número ímpar de opções, que é uma técnica não escalar e unidimensional onde os entrevistados são convidados a indicar o seu nível de concordância ao que for questionado por meio de uma escala ordinal. Segundo Bertram (2009), essa escala de resposta psicrométrica é usada principalmente em questionários para obter preferências ou grau de concordância com uma declaração ou conjunto de declarações dos participantes. Nesta pesquisa, adotaram-se cinco graus de variação, de 0 a 4 , sendo 0 a menor nota, correspondendo à ausência de sustentabilidade. Também foi adotada a possibilidade de se assinalar a opção "Não se aplica" (NA) para estudos em canteiros que não apresentam determinada condição e/ou for um quesito obrigatório excluindo este item da pontuação.

A pesquisa inicialmente procurou obter uma comparação das diretrizes e regras de pontuações dos selos de certificações ambientais a fim de elaborar um instrumento único de observação da sustentabilidade em canteiro de obras. Assim, foi feita uma tabela comparativa baseada nas quatro certificações - LEED (Leadership in Energy and Environmental Design), AQUA (Alta Qualidade Ambiental), BREEAM (Building Research Establishment Assessment Method) e SELO CASA AZUL da Caixa Econômica Federal- e dois autores que serviram como referência de práticas sustentáveis no canteiro de obras - Cardoso e Araújo (2007) e Brandão (2011), como visto no Quadro 1. A última coluna corresponde à nomenclatura e perguntas adotadas na lista de verificação proposta, na qual se baseia esta pesquisa. Neste Quadro1 são apresentadas as questões que devem servir como balizamento para verificar a sustentabilidade no canteiro em relação apenas ao item "Uso Racional da Água". 
Quadro 1 - Fontes de referência e posteriores perguntas do instrumento de pesquisa elaborado

\begin{tabular}{|c|c|c|c|c|c|c|}
\hline LEED & AQUA & BREEAM & Selo Casa Azul & $\begin{array}{c}\text { CARDOSO e } \\
\text { ARAÚJO (2007) }\end{array}$ & BRANDÃO (2011) & $\begin{array}{c}\text { Pergunta da lista de verificação } \\
\text { voltada ao canteiro de obra }\end{array}$ \\
\hline \multicolumn{7}{|c|}{ Captação de água pluvial e cinza } \\
\hline $\begin{array}{l}\text { Projeto para águas } \\
\text { Pluviais controlando } \\
\text { a quantidade e } \\
\text { qualidade }\end{array}$ & $\begin{array}{l}\text { Projeto de águas } \\
\text { pluviais para } \\
\text { Escoamento / } \\
\text { tratamento e } \\
\text { impermeabilização; } \\
\text { Os dispositivos de } \\
\text { coleta devem ser } \\
\text { totalmente separados } \\
\text { das instalações de } \\
\text { água potável }\end{array}$ & $\begin{array}{l}\text { Projeto de águas } \\
\text { pluviais }\end{array}$ & $\begin{array}{l}\text { Retenção e } \\
\text { Aproveitamento de } \\
\text { águas pluviais }\end{array}$ & & $\begin{array}{l}\text { Plano de } \\
\text { reaproveitamento de } \\
\text { águas pluviais }\end{array}$ & 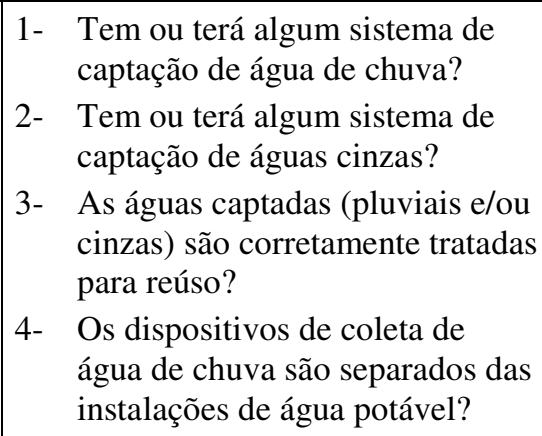 \\
\hline \multicolumn{7}{|c|}{ Tecnologias para águas servidas } \\
\hline $\begin{array}{l}\text { Eficiência na } \\
\text { utilização de água e } \\
\text { tecnologias } \\
\text { inovadoras de } \\
\text { tratamento de águas } \\
\text { servidas }\end{array}$ & $\begin{array}{l}\text { Qualidade sanitária da } \\
\text { água; } \\
\text { Manutenção das } \\
\text { instalações }\end{array}$ & $\begin{array}{l}\text { Garantir qualidade } \\
\text { da água sanitária; } \\
\text { Detecção de } \\
\text { vazamentos de } \\
\text { água e prevenção }\end{array}$ & $\begin{array}{l}\text { Raio mínimo de 2,5 } \\
\text { Km de distância de } \\
\text { Estações de } \\
\text { Tratamento de } \\
\text { Esgoto (ETE) }\end{array}$ & $\begin{array}{l}\text { Prever um correto } \\
\text { sistema para } \\
\text { esgotamento de águas } \\
\text { servidas da obra; } \\
\text { Manutenção periódica } \\
\text { das instalações }\end{array}$ & & 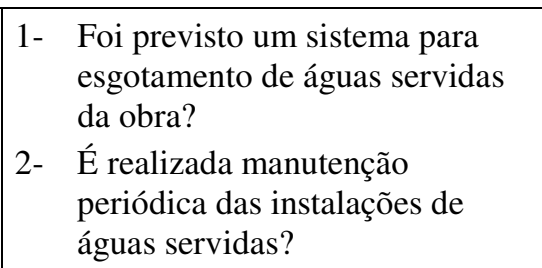 \\
\hline \multicolumn{7}{|c|}{ Redução do consumo } \\
\hline $\begin{array}{l}\text { Redução do } \\
\text { consumo }\end{array}$ & $\begin{array}{l}\text { Controle e redução do } \\
\text { consumo de água } \\
\text { potável; } \\
\text { Caixa de descarga da } \\
\text { bacia sanitária com } \\
\text { capacidade menor ou } \\
\text { igual a } 6 \text { litros }\end{array}$ & $\begin{array}{l}\text { Monitoramento do } \\
\text { consumo de água }\end{array}$ & \begin{tabular}{|l} 
Medição \\
individualizada da \\
água; \\
Dispositivos \\
economizadores- \\
sistema de descarga, \\
arejadores, registro, \\
regulador de vazão
\end{tabular} & $\begin{array}{l}\text { Instalar medidores de } \\
\text { água nas áreas de } \\
\text { vivência, de modo a } \\
\text { conhecer os consumo } \\
\text { e combater os } \\
\text { desperdícios }\end{array}$ & Redução de consumo & 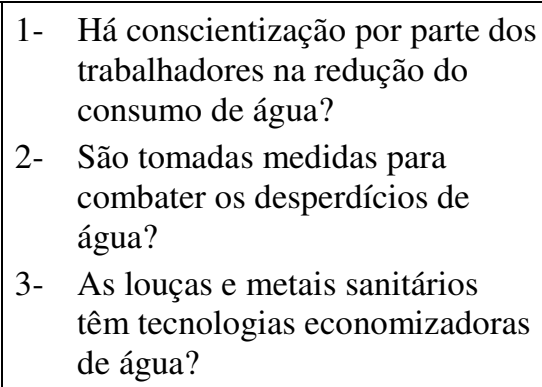 \\
\hline
\end{tabular}


Ao final da análise e identificação dos itens da lista de verificação é feito um cálculo para atribuir uma nota ao canteiro pesquisado. A pontuação é calculada por regra de três, sendo que neste item "Uso Racional da Água", pode ser conhecida a porcentagem de pontuação individual de cada subitem e a soma total do item, dessa forma identificando qual dos três subitens pontuou mais ou menos e a classificação geral do item.

O Quadro 2 exibe um extrato da lista de verificação para o subitem "Tecnologias para Águas Servidas" com as opções de respostas que podem ser assinaladas. Procurou-se elencar as várias possibilidades existentes identificadas na prática e na literatura, estabelecendo que a ponderação seja de acordo com a não realização da prática (nota 0 ) melhorando as características até a melhor pontuação (nota 4).

\section{Quadro 2 - Opção das respostas do subitem “Tecnologias para águas servidas"}

\begin{tabular}{|c|l|}
\hline Pergunta & \multicolumn{1}{|c|}{ Opções de resposta } \\
\hline \multirow{2}{*}{$\begin{array}{c}\text { Foi previsto um } \\
\text { sistema para } \\
\text { esgotamento de } \\
\text { águas servidas da } \\
\text { obra? }\end{array}$} & $0=$ Nenhum \\
\cline { 2 - 2 } & $1=$ Sim, por tubulações provisórias \\
\cline { 2 - 2 } & 2= Sim, apenas banheiro químico com coleta periódica \\
\cline { 2 - 2 } & 4= Sim, por rede pública definitiva \\
\cline { 2 - 2 } & NA= Não é possível assinalar este critério \\
\hline
\end{tabular}

O objetivo da lista de verificação das condições de sustentabilidade em canteiros de obras é apresentar diretrizes de implantação e avaliação da sustentabilidade baseado nas certificações ambientais e literaturas citadas. Também visa propor um método de mensuração de aplicação do conceito nas obras a serem pesquisadas. Com isso, esperase também obter uma faixa de classificação do canteiro segundo os aspectos da sustentabilidade, como no Quadro 3 seguinte.

Quadro 3- Classificação dos canteiros de obras

\begin{tabular}{|c|l|}
\hline Níveis & \multicolumn{1}{|c|}{ Classificação } \\
\hline 0 & canteiro não sustentável $=0 \%$ a $20 \%$ \\
\hline 1 & canteiro com poucas práticas sustentáveis $=21 \%$ a $50 \%$ \\
\hline 2 & canteiro com bom nível de práticas sustentáveis $=51 \%$ a $70 \%$ \\
\hline 3 & canteiro com ótimo nível de práticas sustentáveis $=71 \%$ a $80 \%$ \\
\hline 4 & canteiro com excelente nível de práticas sustentáveis $=81 \%$ a $100 \%$ \\
\hline
\end{tabular}

\section{ESTUDOS DE CASO E RESULTADOS}

Os empreendimentos apresentados neste artigo são quatro, denominados Obra A, Obra B, Obra C e Obra D. Procurou-se restringir a fase dos canteiros estudados, identificando canteiros que estivessem em fase de estrutura e/ou vedação. O Quadro 4 apresenta as principais características de cada obra visitada, identificando se é Habitação de Interesse Social (HIS) ou não.

Foram identificadas várias práticas sustentáveis nestas obras, sendo que algumas referentes ao Uso Racional da Água podem ser observadas nas Figuras 1 e 2 seguintes. $\mathrm{Na}$ Figura 1 pode-se observar que a Obra A e Obra $\mathrm{C}$ possuem sistema adequado de filtragem, armazenagem e refrigeração de água para consumo dos trabalhadores no canteiro; a Obra B utiliza nos banheiros dos trabalhadores descargas de corda, que possui vazão controlada para as descargas dos sanitários evitando o desperdício. 
Quadro 4- Características das obras visitadas

\begin{tabular}{|c|c|c|c|c|}
\hline Obras & Cidade/Estado & Sistema Construtivo & HIS & $\begin{array}{c}\text { Selo de } \\
\text { Certificação }\end{array}$ \\
\hline Obra A & Fortaleza/CE & Alvenaria Estrutural & Sim & Não \\
\hline Obra B & Pindamonhangaba/SP & Alvenaria Estrutural & Não & AQUA \\
\hline Obra C & Fortaleza/CE & Pré-moldado em concreto & Sim & Não \\
\hline Obra D & Limeira/SP & Concreto Armado & Não & AQUA \\
\hline
\end{tabular}

Figura 1- Práticas sustentáveis das Obras A, B e C

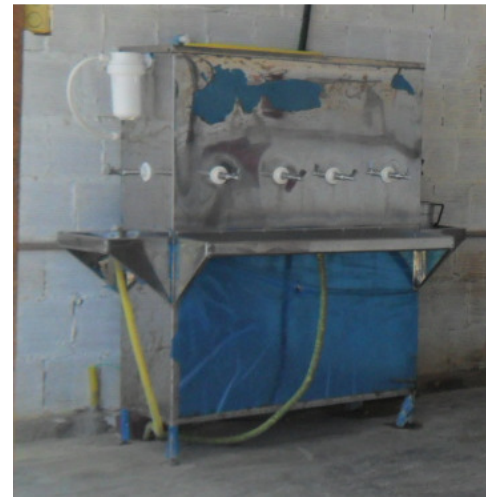

(a) Abastecimento de água para consumo -Obra A

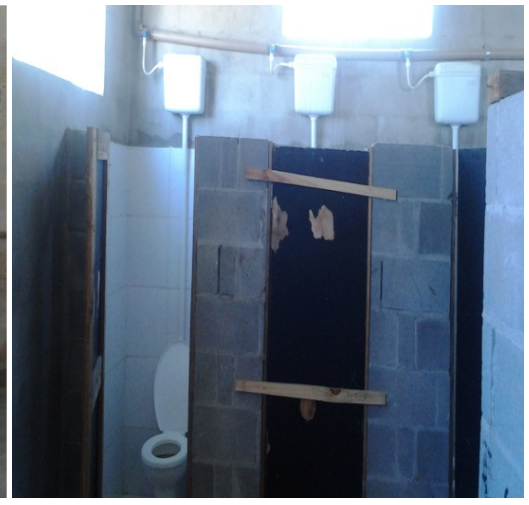

(b)Caixa de descarga acionamento por corda- Obra B

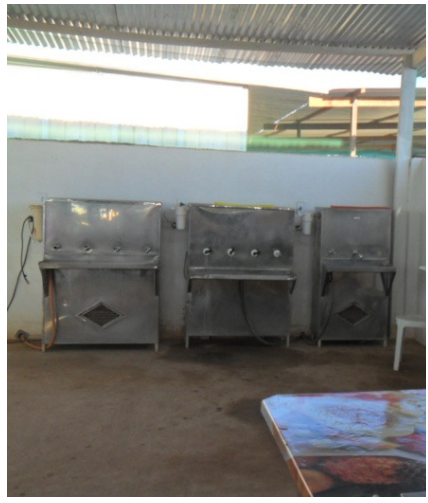

(c)Abastecimento de água para consumo -Obra C

A Obra B utiliza outras duas práticas (Figura 2) que são a aspersão de água no solo com caminhão-pipa para evitar que a poeira suba com água captada da chuva e uma captação de água de chuva simples sem tratamento de água para usos não potáveis.

\section{Figura 2- Práticas sustentáveis da Obra B}

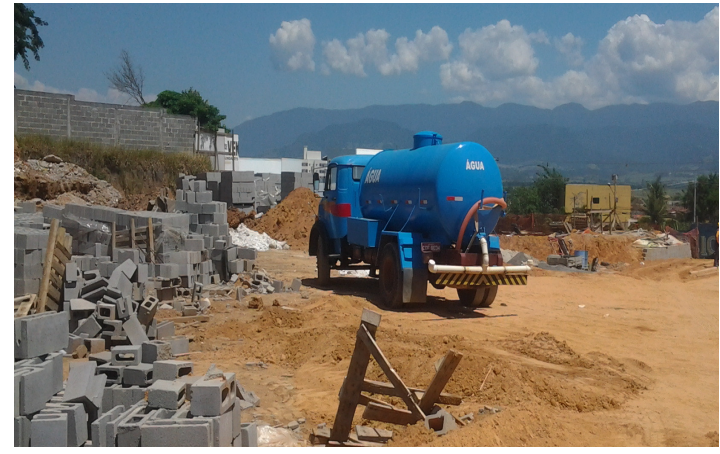

(a) Caminhão pipa para irrigar canteiro

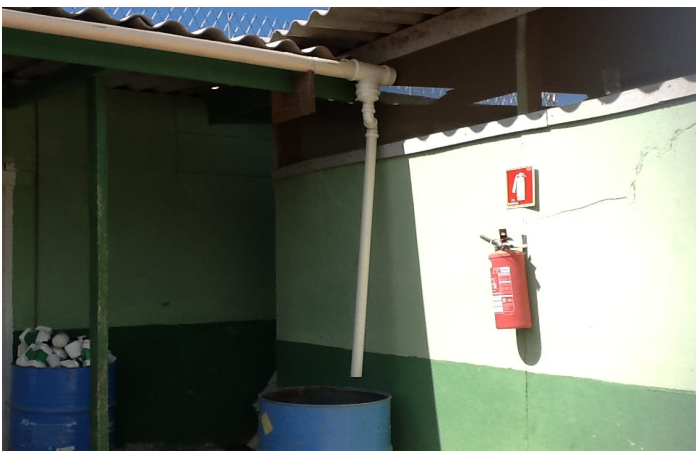

(b) Coleta de água de chuva por telhado

Na Figura 3, são apresentadas algumas práticas utilizadas no canteiro da Obra D a respeito do uso racional da água neste local. Na Figura 3 (a) pode ser visto o sistema de captação de água de chuva por calhas de PVC nas instalações provisórias do canteiro de obras e o uso dos aparelhos de ar-condicionado, onde a água gotejada é reservada para limpeza umidificada dos ambientes. As cisternas para armazenagem e tratamento da água de chuva podem ser vistas na Figura 3 (b), e a torneira com água de reúso para o lava rodas de veículos e lava bicas de caminhões betoneiras pode ser vista na Figura 3 (c). 
Figura 3- Práticas sustentáveis da Obra D

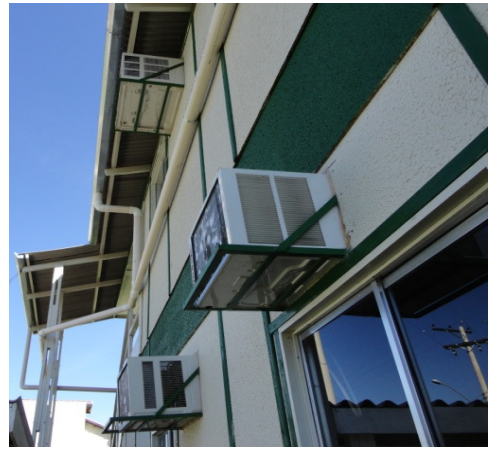

(a) Captação de água de chuva por telhado com calhas de PVC

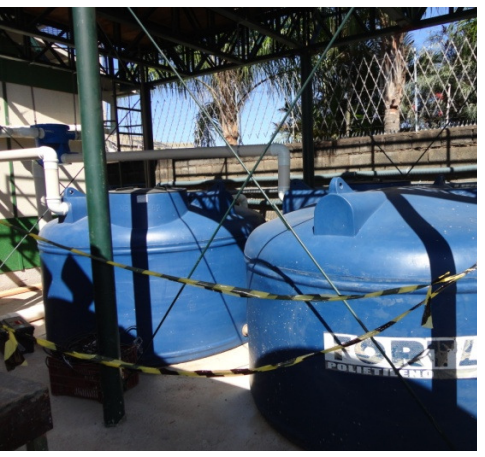

(b) Cisternas para reservar água de chuva após tratamento

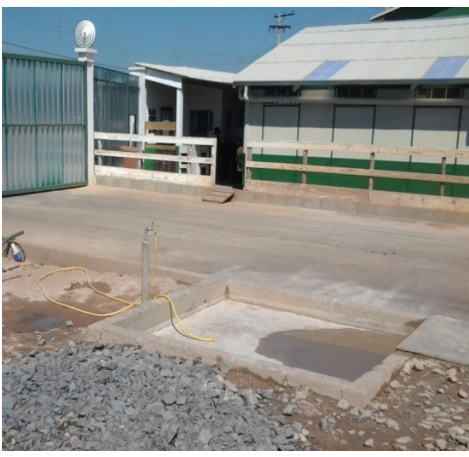

(c) Local para lavagem de rodas e bicas

Ao final, a lista de verificação foi aplicada nestes canteiros para serem avaliadas as práticas sustentáveis ocorrentes em cada canteiro. Os resultados percentuais obtidos em cada subitem podem ser vistos na Figura 4 e na Tabela 1 seguintes.

\section{Figura 4- Gráficos de análise das respostas do item "Uso Racional da Água"}

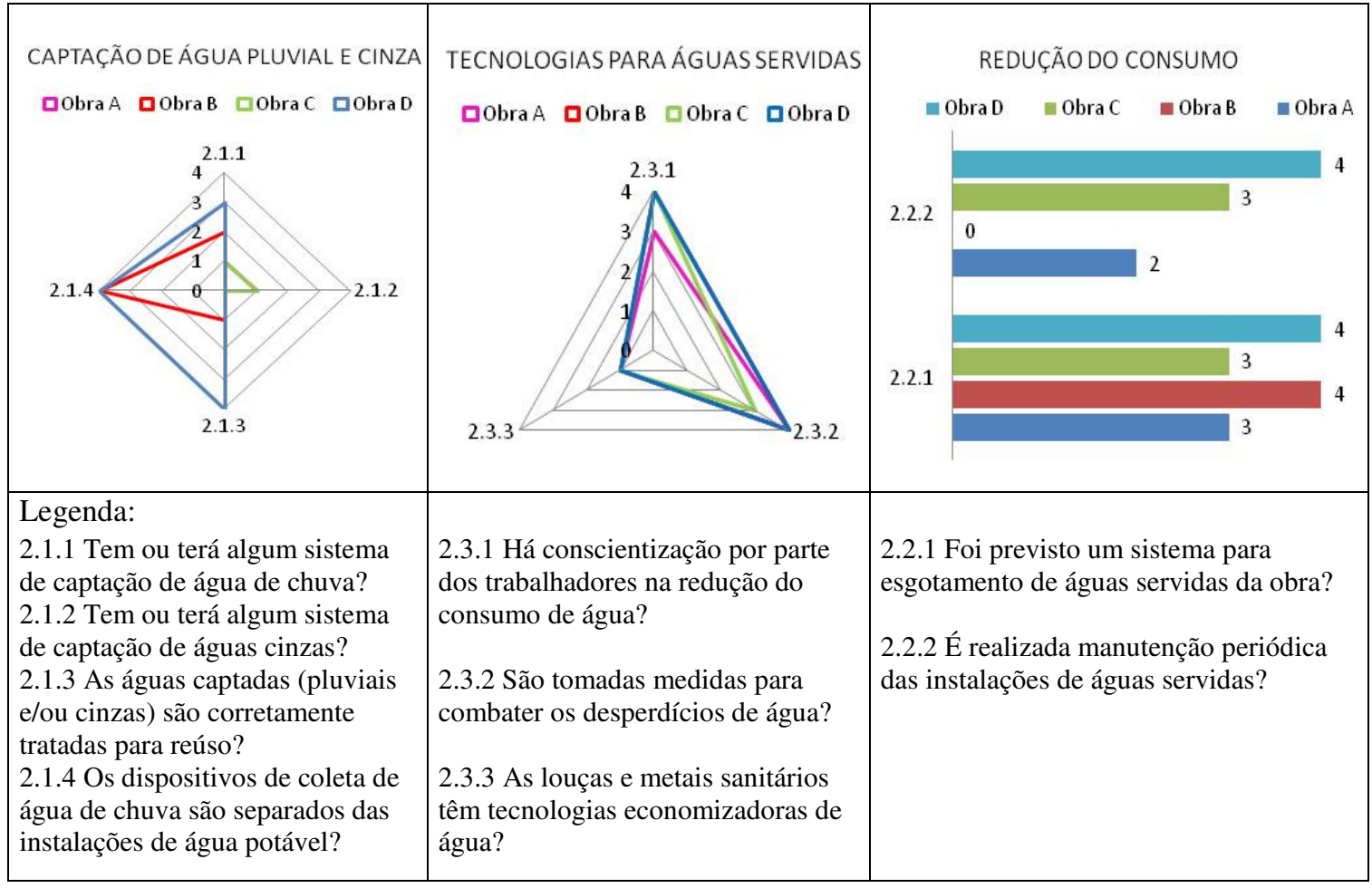

Tabela 1 - Porcentagem do item/subitens e média

\begin{tabular}{|l|c|c|c|c|}
\hline \multicolumn{1}{|c|}{ USO RACIONAL DA ÁGUA } & Obra A & Obra B & Obra C & Obra D \\
\hline Captação de água pluvial e cinza & $0 \%$ & $44 \%$ & $0 \%$ & $69 \%$ \\
\hline Tecnologias para águas servidas & $63 \%$ & $50 \%$ & $75 \%$ & $100 \%$ \\
\hline Redução do consumo & $67 \%$ & $75 \%$ & $67 \%$ & $75 \%$ \\
\hline Média do item por Obra & $\mathbf{4 3 \%}$ & $\mathbf{5 6 \%}$ & $\mathbf{4 7 \%}$ & $\mathbf{8 1 \%}$ \\
\hline
\end{tabular}


Ao final da análise da Tabela 1, pode-se verificar a pontuação final para o item "Uso Racional da Água". Observa-se que a Obra A tem a pior nota se enquadrando no nível 1 - canteiro com poucas práticas sustentáveis, segundo classificação do Quadro 3; a Obra $\mathrm{C}$ também se enquadraria no nível 1 devido à pontuação de $47 \%$. Em relação à Obra $\mathrm{B}$ com 56\% a mesma seria enquadrada no nível 2 - canteiro com bom nível de práticas sustentáveis, e a Obra D, com a melhor pontuação dos quatro canteiros com $81 \%$, estaria no nível 4 - canteiro com excelente nível de práticas sustentáveis. Fazendo comparação com o Quadro 4, verifica-se que as obras B e D, que apresentam certificação AQUA, alcançaram as maiores notas de acordo com o instrumento proposto e apresentam melhores práticas de sustentabilidade no uso da água.

\section{CONCLUSÃO}

Pelos resultados obtidos pode-se avaliar que existem estratégias de uso, reúso e gestão da água nos canteiros de obras, tendo sido encontradas práticas de sustentabilidade nas quatro obras visitadas. Apesar das pontuações terem sido baixas em duas obras, destacase que existem iniciativas visando preservar a água, que é um recurso natural esgotável e que tem sido motivo de grande preocupação atualmente. As melhores pontuações foram obtidas pelas duas obras que possuem selo de certificação ambiental, que apresentam requisitos mínimos que devem ser atendidos desde a etapa de execução; mas, mesmo assim, a Obra B não obteve uma nota adequada à classificação de obra sustentável.

Destacou-se que nas Obras A e C, que são empreendimentos HIS, as notas foram nulas no subitem de "Captação de águas pluviais e cinzas". Acredita-se que poderia haver iniciativas por parte do contratante, no caso dos governos, para solicitar o uso deste tipo de prática durante as fases de execução e de ocupação.

Por fim, ressalta-se que ferramentas como a lista de verificação proposta pode servir como subsídio para a melhoria da implementação da sustentabilidade na construção civil, e principalmente no canteiro de obras, que é a fase de maior movimentação e ocorrências durante o processo de construção, e que proporciona benefícios sociais e econômicos para o empreendimento, além dos ambientais.

\section{AGRADECIMENTOS}

A CAPES, Rede Pró-engenharias, e à FINEP, Rede CANTECHIS, pelo apoio na realização da pesquisa.

À Fundação de Amparo à Pesquisa do Estado de São Paulo (FAPESP), processo ${ }^{\circ}$ 2014/16362-1, pelo apoio na divulgação da pesquisa.

\section{REFERÊNCIAS}

ASSOCIAÇÃO BRASILEIRA DOS ESCRITÓRIOS DE ARQUITETURA (ASBEA). Guia de Sustentabilidade na Arquitetura: diretrizes de escopo para projetistas e contratantes. São Paulo: Prata Design, 2012.

ASSOCIAÇÃO BRASILEIRA DE NORMAS TÉCNICAS (ABNT). NBR 13969: Tanques sépticos: unidades de tratamento complementar e disposição final dos efluentes líquidos: projeto, construção e operação. Rio de Janeiro, 1997.

ASSOCIAÇÃO BRASILEIRA DE NORMAS TÉCNICAS (ABNT). NBR 15527: Água de chuva: aproveitamento de coberturas em áreas urbanas para fins não potáveis. 8 p. Rio de Janeiro, 2007.

BERTRAM, D. Likert Scales. Topic Report, University of Belgrade, Serbia, 2009. 
BRANDÃO, G. B. M. Tecnologias e Certificações para Canteiros Sustentáveis. 2011. 66f. Trabalho de Conclusão de Curso de Engenharia Civil da Universidade Federal de São Carlos.

BRASIL. Lei no. 9.433, de 08 de janeiro de 1997. Institui a Política Nacional de Recursos Hídricos. Diário Oficial da República Federativa do Brasil, Brasília, DF, seção 1, p. 470, v. 135, n. 6, 09 de janeiro de 1997.

BRASIL. Ministério do Meio Ambiente. Construção Sustentável. 2014a. Disponível em:<http://www.mma.gov.br/cidadessustentaveis/urbanismosustentavel/constru\%C3\%A7\%C3\%A3osustent\%C3\%A1vel>. Acesso em abril de 2014.

BRASIL. Ministério do Meio Ambiente. Conselho Nacional de Meio Ambiente (CONAMA). Resolução $\mathbf{n}^{\mathbf{0}}$ 357, de 17 de março de 2005. "Dispõe sobre a classificação dos corpos de água e diretrizes ambientais..." Disponível em:<http://www.mma.gov.br/port/conama/res/res05/res35705.pdf>. Acesso em abril de 2014.

BRASIL. Ministério do Trabalho e Emprego. Norma Regulamentadora $\mathbf{n}^{\mathbf{0}}$ 18: Condições e meio ambiente de trabalho na indústria da construção. 2014b. Disponível em:<http://portal.mte.gov.br/legislacao/norma-regulamentadora-n-18-1.htm $>$. Acesso em fevereiro de 2014.

BRASIL. Ministério da Saúde. Portaria MS no 2914 de 12/12/2011. Dispõe sobre os procedimentos de controle e de vigilância da qualidade da água para consumo humano e seu padrão de potabilidade. Disponível em:<http://bvsms.saude.gov.br/bvs/saudelegis/gm/2011/prt2914_12_12_2011.html>. Acesso em julho de 2014.

CARDOSO, F.F.; ARAUJO, V.M. Levantamento do estado de arte: canteiro de obras. 2007. 38p. Projeto Finep: Tecnologias para construção habitacional mais sustentável. São Paulo, SP.

COMPANHIA AMBIENTAL DO ESTADO DE SÃO PAULO (CETESB). Reúso de água. 2014. Disponível em:<http://www.cetesb.sp.gov.br/agua/\%C3\%81guas-Superficiais/39-Reúso-de\%C3\%81gua >. Acesso em julho de 2014.

ENVIRONMENTAL PROTECTION AGENCY (EPA). Guidelines For Water Reuse. Washington, 2012. Disponível em: <http://nepis.epa.gov/Adobe/PDF/P100FS7K.pdf $>$. Acesso em julho de2014.

GIACCHINI, M. Uso e Reúso da Água. Série de Cadernos Técnicos. CREA-PR, 2011.

HALLIDAY, S. Sustainable Construction. Burlington, USA: Butterworth-Heinemann, 2010.

REIS, R.P.A.; SOUZA, U.E.L.; OLIVEIRA, L.H. Alternativas e Soluções de Instalações Hidráulicas Provisórias em Canteiros de Obras. 10p. 2004. In: I Conferência Latino-Americana de Construção Sustentável - X Encontro Nacional de Tecnologia no Ambiente Construído. Anais... São Paulo.

SANTOS, C.; TAVEIRA-PINTO, F.; CHENG, C.Y.; LEITE, D. Development of an experimental system for greywater reuse. Faculdade de Engenharia da Universidade do Porto, Portugal, 2011.

UNITED STATES GREEN BUILDING COUNCIL (USGBC). Disponível em: $<$ http://www.gbcbrasil.org.br> Acesso em julho de 2013.

VALENTE, J. P. Certificações na Construção Civil: comparativo entre Leed e HQE. 2009. 71p. Rio de Janeiro: Escola Politécnica, Universidade Federal do Rio de Janeiro.

WORLD COMMISSION ON ENVIRONMENT AND DEVELOPMENT (WCED). 1987. Our Common Future: The Bruntland Report. United Nations World Commission on Environment and Development. Oxford University Press. New York, NY.

YIN, R.K. Case Study Research: design and methods. 4th.ed. Thousand Oaks: SAGE Publications. 2009. (Applied Social Research Methods Series; v.5).

ZEULE, L.O. Práticas e avaliação da sustentabilidade em canteiros de obras. 2014. 268f. Dissertação (Mestrado em Estruturas e Construção Civil). Universidade Federal de São Carlos, São Carlos, 2014. 